\title{
INVESTIGACIÓN
}

Recibido: 10/10/2019 --- Aceptado: 17/12/2019 --- Publicado: 15/06/2020

\section{LA IMBRICACIÓN Y DISOLUCIÓN DE LA MASA EN EL PÚBLICO, SUS CONSECUENCIAS: LA INESTABILIDAD POLÍTICA DE LOS SISTEMAS LIBERALES}

\section{The imbrication and dissolution of the mass in the public, its consequences: the political instability of liberal systems}

Ciro Enrique Hernández Rodríguez¹. Universidad de La Laguna. España. chernanr@ull.edu.es

\section{RESUMEN}

Un rápido vistazo a las actuales coyunturas políticas en los sistemas políticos liberales que con tanto éxito estuvieron organizando hasta la última crisis económica del 2008 a las sociedades occidentales desde la conclusión de la II Guerra Mundial, permite comprobar el estado más o menos caótico en el que se encuentran muchos de ellos. Lo que en otros tiempos fue con contadas excepciones un remanso político bipartidista de alternancias entre dos fuerzas políticas mayoritarias y hegemónicas, hoy es un galimatías de fuerzas políticas atomizadas y dispersas en todo el espectro político. Sin quitar su responsabilidad a la crisis, existen determinadas causas relacionadas con los cambios en la composición social de la Opinión Pública y la irrupción de las nuevas Tecnologías de la Información y la Comunicación que explican la gran inestabilidad que se ha apoderado de los sistemas políticos occidentales. La presente investigación cualitativa desarrolla una pertinente argumentación explicativa que revela la forma en la que los cambios institucionales han venido afectando a la tradicional esfera social pública, desde la que todavía se legitiman los gobiernos de los sistemas liberales durante los procesos políticos.

PALABRAS CLAVE: política - ideología - sociedad - opinión pública - masa público - TIC - información - actualidad.

\section{ABSTRACT}

A quick look at the current political conjunctures in the liberal political systems that were successfully organizing Western societies from the end of World War II until the last economic crisis of 2008, allows us to verify the more or less chaotic state in which many of them are found. What was once with few exceptions a bipartisan political backwater of alternations between two major and hegemonic political forces

1 Ciro Enrique Hernández Rodríguez: Universidad de La Laguna. España. chernanr@ull.edu.es 
Hernández Rodríguez, C. E.

La imbricación y disolución de la masa en el público, sus consecuencias: la inestabilidad

política de los sistemas liberales

today is a gibberish of atomized and dispersed political forces throughout the political spectrum. Without removing its responsibility for the crisis, there are certain causes related to changes in the social composition of Public Opinion and the emergence of new Information and Communication Technologies that explain the great instability that has gripped Western political systems. This qualitative research develops a pertinent explanatory argument that reveals the way in which institutional changes have been affecting the traditional public social sphere, from which the governments of liberal systems are still legitimized during political processes.

KEYWORDS: politics - ideology - society - public opinion - mass - public - CIT information - news.

\section{A IMBRICAÇÃO E DISSOLUÇÃO DA MASSA NO PÚBLICO, SUAS CONSEQUÊNCIAS: A INSTABILIDADE POLÍTICA DOS SISTEMAS LIBERAIS}

\section{RESUMO}

Um rápido olhar para as atuais conjunturas políticas nos sistemas políticos liberais que com tanto sucesso estiveram-se organizando até a última crise econômica de 2008 as sociedades ocidentais desde a conclusão da II Guerra Mundial, permite comprovar o estado mais ou menos caótico no que se encontram muitos deles. O que em outros tempos foi com contadas exceções um remanso político bipartidário de alternações entre duas forças políticas majoritárias e hegemônicas hoje é um galimatias de forças políticas atomizadas e dispersas em todo o espectro político. Sem tirar sua responsabilidade na crise, existem determinadas causas relacionadas com as mudanças na composição social da Opinião Pública e a irrupção das novas Tecnologias da Informação e da Comunicação que explicam a grande instabilidade que assumem os sistemas políticos ocidentais. A presente pesquisa qualitativa desenvolve uma pertinente argumentação explicativa que revela a forma na qual as mudanças institucionais chegaram afetando a tradicional esfera social pública, a partir da qual ainda se legitimam os governos dos sistemas liberais durante os processos políticos.

PALAVRAS CHAVE: política - ideología - sociedade - opinião pública - massa público - TIC - informação - atualidade.

\section{Cómo citar el artículo:}

Hernández Rodríguez, C. E. (2020). La imbricación y disolución de la masa en el público, sus consecuencias: la inestabilidad política de los sistemas liberales. [The imbrication and dissolution of the mass in the public, its consequences: the political instability of liberal systems].Vivat Academia. Revista de Comunicación, (151), 47-68. doi: http://doi.org/10.15178/va.2020.151.47-68. Recuperado de

http:// www.vivatacademia.net/index.php/vivat/article/view/1206

Vivat Academia. Revista de Comunicación. 15 junio 2020 /15 septiembre 2020, nº 151, 47-68 
Hernández Rodríguez, C. E.

La imbricación y disolución de la masa en el público, sus consecuencias: la inestabilidad

politica de los sistemas liberales

\section{INTRODUCCIÓN}

El análisis sobre la transformación de la institución social de la Opinión Pública que ofrecemos a continuación es el resultado de una lectura crítica y complementada de la obra de Jurhen Habermas Historia y crítica de la Opinión Pública. Consideramos que estos cambios específicos, y las transformaciones institucionales en general, todos los que se operaron en el transcurso del tiempo, son la clave que explica el surgimiento histórico y la posterior evolución de la Opinión Pública tal y como la conocemos hoy en día.

Lo relevante de la labor de Habermas en el seguimiento a través de su historia de esta institución consiste en que, adecuadamente reinterpretada con otros nuevos criterios, nos ofrece una clave fundamental para la comprensión de esta crisis de legitimación política cada vez más manifiesta a la que estamos asistiendo.

Por un lado, tenemos la ampliación en la base social que componía al público originario y que es el resultado de la extensión social de la racionalidad que lo caracterizó desde sus inicios, por entonces minoritario. Por el otro lado, hoy en día la institución de la Opinión Pública se encuentra además afectada por la pérdida del monopolio de la influencia ejercida sobre ella por los medios de información tradicionales, prensa, radio y televisión, desde su surgimiento en la modernidad hasta la irrupción de las redes sociales digitales.

El control político sobre una ciudadanía, que antaño tuvo una base social distinta y estaba inerme por su falta de racionalidad ante su exposición a unos medios cuyos mensajes además no se podían contestar en la misma escala masiva en la que eran difundidos, hoy se convierte en una inmanejable dispersión de las preferencias políticas. Una parte significativa de los electores actualmente se decantan por opciones en los márgenes del espectro político o por una abstención que cuestionan todo el entramado constitucional liberal, amenazando la estabilidad de aquellos sistemas formalmente democráticos que han venido caracterizando a las sociedades occidentales.

\section{OBJETIVOS}

Lo que ofrecemos a continuación es una explicación de estos cambios en su composición social del público originario hasta la actualidad para poder entender como la racionalidad crítica sirvió a esa legitimación de un orden político liberal que hoy se enfrenta a su crisis institucional. Nuestro objetivo será pues el de concluir exponiendo estos cambios como una de las causas de esta crisis.

No obstante su importante papel como otra causa de dicha crisis, la segunda parte sobre el efecto y la contribución de las redes a la inestabilidad política no serán objeto del presente trabajo.

Vivat Academia. Revista de Comunicación. 15 junio 2020 /15 septiembre 2020, nº 151, 47-68 
Hernández Rodríguez, C. E.

La imbricación y disolución de la masa en el público, sus consecuencias: la inestabilidad

politica de los sistemas liberales

\section{METODOLOGÍA}

El carácter de la presente investigación cualitativa es descriptivo. Aunque esta categorización debería bastar para comprender la naturaleza netamente explicativa que desarrolla, hacer una breve contextualización metodológica sin duda que ayudará a situar mejor su objeto de investigación.

Las instituciones sociales, como la Opinión Pública y los gobiernos en las sociedades liberales, son tratadas por la teoría estructural-funcionalista como partes de un sistema en el que las funciones, debidamente delimitadas, de sus subsistemas y su interacción deben contribuir a la reproducción de su homeostasis o equilibrio para garantizar su continuidad y pervivencia. Tal y como anticipamos, a continuación ofrecemos la explicación de la hoy problemática interacción entre la institución de la Opinión Pública y el gobierno a partir de la ruptura del equilibrio entre ellos debida a los cambios en la composición social de la primera.

Cabría pensar que por eso solo podemos adscribir este desarrollo exclusivamente a la metodología estructuralista y funcionalista, pero esto no es así de cierto. Precisamente, a pesar de la polémica entre ambos enfoques a los dos lados del Atlántico, la referencia a Habermas, figura destacada del Instituto de Ciencias Sociales en Frankfort, nos permite adscribir también esta explicación a la Teoría Crítica. Tal es así que a lo largo de la discusión en todo momento nos ajustamos a esta breve sentencia metodológica de Max Horkheimer:

[...]porque la verdad se forma en una evolución de ideas que se transforman y luchan entre sí. El pensamiento permanece en gran parte fiel a sí mismo en tanto en cuanto está dispuesto a contradecirse, conservando a la vez - como momentos inmanentes de verdad - el recuerdo de procesos a los que debe su propia existencia. (Horkheimer 2002, p. 93)

Con carácter general, toda la indagación que desarrollamos en el siguiente apartado de discusión se atiene a lo significado literalmente por esta breve sentencia.

\section{DISCUSIÓN}

En realidad, el punto de inicio de este análisis es otro estudio previo sobre los conceptos de masa y de público realizado a partir de aquellos autores que en su momento estimamos los más relevantes para ofrecernos la noción más completa y contrastada de ambos. La mayoría de estos autores aparecen referidos desde el comienzo, por eso el recurso a sus ideas y citas anteriores serán constantes.

Con todo, consideramos que el desarrollo de las ideas de masa y público contenidos a lo largo del presente análisis es suficiente para darle sentido y coherencia hasta llevarlo a su objetivo, aunque lo mejor sería el poder acceder a los desarrollos previos a partir de su publicación para completar el presente.

Vivat Academia. Revista de Comunicación. 15 junio 2020 /15 septiembre 2020, nº 151, 47-68 
Hernández Rodríguez, C. E.

La imbricación y disolución de la masa en el público, sus consecuencias: la inestabilidad política de los sistemas liberales

Así, justo al inicio, el siguiente epígrafe hace referencia al clásico análisis que reproduce Habermas respondiendo a su necesidad de explicar el modo en el que se transforma la publicidad - entendida como el ámbito de lo público, no el de la promoción comercial - como consecuencia de la irrupción de los sectores sociales originariamente excluidos en la creación del Estado burgués de derecho. La presión política ejercida por las masas, a través de las movilizaciones sociales, de sus organizaciones y de sus partidos, sobre sus gobiernos políticos para que intervinieran en el tráfico mercantil en defensa de sus derechos e intereses es lo que ha ido borrando la nítida separación entre lo público y lo privado. No olvidemos que fue esta separación lo que posibilitó la aparición del público primigenio en el curso de la modernidad al constituirse los Estados burgueses de derecho.

\subsection{Contraste y perfusión de los conceptos de masa y público}

Lo más conveniente a nuestros efectos es comprender aquella interpenetración de la sociedad en el Estado y del Estado en la sociedad; o lo que es lo mismo, comprender la progresiva desaparición de la separación entre lo público y lo privado. Es la presión de la sociedad sobre el Estado para ampliar sus funciones y para regular los variados aspectos del tráfico mercantil lo que está en el origen del intervencionismo que da lugar al Estado social y a la sociedad de masas.

En realidad, si lo pensamos detenidamente, la limitación que quiso imponer el primer liberalismo a la esfera pública está en el mismo origen de ese sentido cargado de negatividad que arrostra el concepto de masa.

Ya aquellos primeros liberales, Mill y Tocqueville, a los que cita Habermas, descubrieron alarmados los efectos que, por entonces, estaba produciendo la publicidad burguesa después del tiempo en el que acabó por desbancar a la publicidad representativa estamental. La irrupción de las clases sociales desposeídas en la esfera pública empezó a ser percibida por ellos como una nueva instancia de dominación alternativa a la del gobierno político de la sociedad, como una nueva amenaza. Esto se debió precisamente a las mismas funciones críticas y de control del poder que tenía atribuidas la publicidad burguesa. El hasta entonces restringido ámbito de la publicidad burguesa había quedado reservado para las personas privadas que tuvieran autonomía y que por eso podían insertarse en esa publicidad. Ésta autonomía sólo la podían garantizar, dentro del tráfico mercantil entendido como el ámbito propiamente diferenciado del Estado -la sociedad civil-, la propiedad y la instrucción.

Como muy bien relata Habermas, la progresiva limitación en el acceso a la propiedad que conllevó el proceso de acumulación capitalista en las primeras fases de la industrialización y la expansión comercial a escala global, puso de manifiesto el estrecho margen para la legitimación del poder sometido a la crítica y al control de la opinión pública cuando amplias capas sociales pugnaron por acceder a la esfera pública. La crítica acabó por reducir su eficacia a la apariencia de ella misma. 
Hernández Rodríguez, C. E.

La imbricación y disolución de la masa en el público, sus consecuencias: la inestabilidad política de los sistemas liberales

Los conflictos de clase se manifestaron entonces en esa esfera pública. Las masas, a través de sus organizaciones y partidos, irrumpieron en ella reclamando la intervención del Estado mediante la ampliación de sus funciones sociales y la regulación del tráfico mercantil para hacer efectivo un principio de igualdad sólo formalmente proclamado por las constituciones.

De esta prejuiciosa y conservadora consideración sobre las masas sobradamente documentada -a las que Mill, Tocqueville y Tarde trataban de muchedumbre; Le Bon, Ortega y Gasset, Max Scheler, Oswald Spengler, Hanna Arendt desprecian; Canetti, estudia como a un ser indómito y destructivo; incluso Adorno y Horkheimer, y el propio Habermas, las ven todavía con un bienintencionado y condescendiente recelo- es de donde procede la voluntad de establecer la diferenciación tajante entre masa y público, y de mantener a la masa a efectos de su categorización fuera de la participación política mediante el sufragio censitario.

Pero en realidad, los procesos de progreso social que se han ido generalizando en todas las sociedades democráticas industrializadas avanzadas por la acción de las propias masas permiten hacer una nueva relectura de ésta categoría que, a estas alturas, sólo parece formar parte esencial de un discurso de tintes claramente conservadores.

Muy al contrario, el término público nació con el marchamo de prestigio que, en tiempos de la publicitad representativa estamental, le confería el ser atributo del rey, de la nobleza y de la misma representación estamental. Estos simbolizaban a la nación. Esa aura de estimación y deferencia hacia lo público se trasladará al público propiamente entendido con el surgimiento del Estado liberal burgués de derecho. Esto ocurrió gracias al descubrimiento de la imprenta y a la agitación política que se hizo entonces posible por la difusión masiva de la publicidad literaria. El proceso acabó por originar a un público con las características de la ilustración, a un público ilustrado y racionante. Reproduciendo la cita de Habermas, es:

El proceso en el cual el público compuesto por personas privadas racionantes se apropia de la publicidad reglamentada desde arriba, convirtiéndola en una esfera crítica del poder público, se completa con la transformación del funcionamiento de la publicidad literaria, dotada ya con organizaciones del público y con plataformas de discusión. [...] (Habermas 2011, p. 88)

"[...] Finalmente, la publicidad burguesa desarrollada acaba basándose en la ficticia identidad de las personas privadas reunidas en calidad de público en sus roles de propietario y hombre". (op. cit. 92). Sólo con las transformaciones del Estado burgués de derecho el término público empieza adquirir connotaciones peyorativas. La ya descrita irrupción de las masas en la esfera pública y la interpenetración del Estado y la sociedad, despiertan un profundo recelo entre los liberales, tan temerosos como estaban que el orden socioeconómico capitalista legado por la modernidad se pudiera ver comprometido. Entonces el discurso liberal elabora una argumentación ad hoc para prevenir el efecto del creciente protagonismo del Estado en la sociedad y 
Hernández Rodríguez, C. E.

La imbricación y disolución de la masa en el público, sus consecuencias: la inestabilidad

política de los sistemas liberales

viceversa. La economía política liberal tratará de imponer, a modo de axioma teórico, la ineficacia y la ineficiencia de la iniciativa pública frente a la privada en el tráfico mercantil con la voluntad premedita de retrotraer al Estado en la sociedad hacia sus dimensiones mínimas, las mismas que sólo se dieron en el capitalismo primigenio durante el tránsito de la sociedad estamental al Estado liberal burgués de derecho.

Pero más bien parece que el mercado -el tráfico mercantil- con el transcurso del tiempo se muestra cada vez más incapaz e inoperante frente a las generalizadas demandas sociales a las que no alcanza para atender. Las externalidades económicas aumentan. Al discurso liberal le resulta cada vez difícil cuestionar ante las propias masas, convertidas en público dotado de notoriedad pública crítica a través de sus organizaciones, su reconocimiento hacia las socializadas instancias estatales que se ocupan de garantizar la atención a sus derechos sociales.

Lo público se revalúa por su propio desempeño social frente a la propensión de lo privado hacia el lucro de una iniciativa que muchas veces se extingue ante su incapacidad para satisfacerlo. Cada vez más, lo privado es percibido como negocio particular y lo público como servicio a la comunidad. Esto es precisamente parte del proceso que lleva al desdibujamiento de la separación entre lo público y lo privado al que se refiere Habermas. Aunque él lo explica de una manera mucho más extensa y pormenorizada, los potenciales beneficiarios de la acción social del Estado se perciben a sí mismos como personas privadas por el mismo origen y evolución de la privacidad inserta en el tráfico mercantil. Pero aceptan y reclaman del Estado que les sustraiga de ese tráfico para que satisfaga sus necesidades de distinto orden ante su propia incapacidad para lograr satisfacerlas por sí mismos en las condiciones inequitativas del mercado.

Buena prueba de la prevalencia en la estimación social de lo público nos la ofrecen los significados del término público que según el DRAE todavía se conservan en el leguaje más común. Ninguno de los siete significados allí contenidos posee connotaciones peyorativas. En todo caso, a nosotros, más que la dialéctica públicoprivado, lo que nos debe preocupar es el contraste entre masa y público, y mejor que eso la tendencia a la desaparición de la separación entre ambos conceptos.

\subsection{El público como masa y la masa como público}

En más de una ocasión, alguno de los autores que citamos ha querido valerse de la diferenciación masa/público para establecer sus propias categorías. Eso pasó con Tarde, aunque él utilizaba el término multitud y no el de masa frente al de público. También pasaba con James E. Grüning y Todd Hunt. En su obra Dirección de relaciones públicas citan al sociólogo Herbert Blumber y al filósofo John Dewey como los presumibles autores de un concepto de público obtenido por contraste con el de masas:

Por ejemplo los científicos sociales, las empresas de la investigación comercial y los Relaciones Públicas «miden la opinión pública» a través de encuestas o sondeos. La definición de «público» de Blumer y Dewey deja bien claro que

Vivat Academia. Revista de Comunicación. 15 junio 2020 /15 septiembre 2020, nº 151, 47-68 
Hernández Rodríguez, C. E.

La imbricación y disolución de la masa en el público, sus consecuencias: la inestabilidad

política de los sistemas liberales

estos sondeos pueden medir opiniones, pero no las de los públicos, sino de las de las masas.

[...] La masa es heterogénea, un público es homogéneo. Los individuos forman una masa no porque tengan algo en común, sino porque todos sintonizan el mismo medio de comunicación o resulta, sencillamente, que viven en la misma ciudad o país. Los miembros de un público, por contra, tienen algo en común. Están afectados por el mismo problema o tema. (Grüning y Hunt 2003, pp. 234-235)

Blumer y Dewey deciden que la medida demoscópica de la opinión no es la del público, sino la de la masa. Para establecer esta diferenciación, atribuyen propiedades distintas a uno y a otra. Según Grüning y Hunt la masa es heterogénea y el público homogéneo.

En realidad, a la forzada acotación de masa reducida así a aquellos que sintonizan el mismo medio de comunicación o que resulta, sencillamente, que viven en un país, acotación imposible de casar con los amplios y sofisticados criterios que refieren la práctica totalidad de los autores consultados sobre el concepto de masa, además de ello también se sigue que el público sólo se constituye en un momento muy preciso y ya segregado como grupo al que exclusivamente une la existencia de un problema común.

Sin duda que a Grüning y Hunt las restricciones en las nociones de masa y público que pudieron tomar de Blumber y Dewey les resultaron muy convenientes para realizar su posterior tipología de los públicos con la voluntad de explicar su diseño de estrategias para la comunicación persuasiva o la adecuación de la política y la práctica institucionales según criterios de rentabilidad económica para la construcción del good will. Pero John Dewey en su obra se refiere al público, en singular, como un elemento clave del Estado cuya extensión no es ni mucho menos lo limitada ni lo homogénea que nos la presentan estos autores.

En su caso, de ser esto como sostienen Grüning y Hunt, entonces quedaría invalidada toda la teoría que Habermas desarrolla para explicar la constitución del público. En realidad parece que Dewey y Habermas se están refiriendo precisamente al mismo sujeto político de la opinión: “[...] Finalmente, la publicidad burguesa desarrollada acaba basándose en la ficticia identidad de las personas privadas reunidas en calidad de público en sus roles de propietario y hombre". (Habermas 2011, p. 92)

Alternativamente, y en línea con la propuesta de Grüning y Hunt, cabe suponer que el «único» problema común que une al público en su constitución sea el control crítico del poder político en el Estado liberal burgués de derecho; pero esto, evidentemente, no sólo es que no pueda ser un momento preciso, además resulta que el control crítico del poder se descompone en el curso de un permanente debate y discusión en todas las cuestiones que tengan que ver con el tráfico mercantil. Esta 
Hernández Rodríguez, C. E.

La imbricación y disolución de la masa en el público, sus consecuencias: la inestabilidad política de los sistemas liberales

explicación se puede convalidar perfectamente con la misma idea de Dewey sobre el alcance de las indirectas consecuencias de las transacciones (Dewey 2004, p. 65).

El universo de intereses en permanente pugna exige de ese público que tenga por definición una composición muy heterogénea, exactamente la que expone Habermas cuando nos explica la enorme variedad social de personas privadas que concurren en ese público primigenio: aristócratas y burgueses ilustrados, comerciantes, artesanos, científicos, escritores y editores, críticos de arte, de literatura, de la moral pública y privada... A veces, en esa ficticia identidad con la que el público se percibe a sí mismo, el mismo requisito que le impone Dewey para su mera existencia, Habermas habla de públicos para explicar que éste se sabe mucho más amplio y heterogéneo de lo que aparenta.

Pero aún más crítica e inconsistente se volverá la consideración sobre un público homogéneo en la medida que la base de la publicidad se amplía enormemente con las transformaciones del Estado liberal burgués hacia el Estado social. Con todo, todavía cabe suscribir la objeción de Habermas a su consideración como público de unas masas incorporadas a la esfera pública por la pérdida de la notoriedad pública crítica que acompaña al proceso. De esta cuestión trataremos de dar cuenta más adelante. Aquí nos interesa ahora resolver aquella otra contraposición público/masa que cierra la obra de Habermas cuando cita a C.W. Mills. Nosotros pensamos que la enumeración de características que realiza este último cuando se refiere al público adolece de una función esencial. Consideramos que la opinión -en todo momento nos hemos referido al público como portador de opinión pública- solo se puede realizar entre las personas privadas que integran un público mediada por la actualidad.

Ni mucho menos pensamos que la actualidad sea el único sustrato estructural en el que se apoya y crece la opinión. Los medios no determinan la opinión, tan sólo la influyen. El proceso es mucho más complejo y en el origen de la opinión intervienen otros factores, como pudiera ser la racionalidad o, de un modo más específico, la ideología. En su caso no concebimos que la crítica del público se pueda construir sin un objeto que, como regla general, lo constituye la actualidad o alguno de sus aspectos más peculiares.

Aceptaríamos aquí que una parte de la actualidad no esté dictada por la agenda de los medios de comunicación de masas convencionales -sobre todo con el desarrollo espectacular de la autocomunicación de masas (Castells, 2009, pássim) en la web y a través de las redes sociales-, pero en todo caso aún seguiría existiendo un casi obligado arbitraje de los medios de comunicación de masas tradicionales que son, por definición, los portadores de la actualidad.

No nos cabe ninguna duda de que esta consideración sobre el papel de los medios de comunicación de masas entre un público portador de opinión, crítica o no, no se puede soslayar en la caracterización de ese público. De este modo, la estricta separación entre público y masa -para esta última él reserva en exclusiva la

Vivat Academia. Revista de Comunicación. 15 junio 2020 /15 septiembre 2020, nº 151, 47-68 
Hernández Rodríguez, C. E.

La imbricación y disolución de la masa en el público, sus consecuencias: la inestabilidad política de los sistemas liberales

mediatización de los propios medios de comunicación de masas- a la que se refiere C.W. Mills, en realidad no existe, porque los medios de comunicación de masas son esenciales en la constitución del público portador de opinión. Por eso tendremos que referirnos obligatoriamente a la imbricación público/masa, tal como nos hemos propuesto en demostrar y también por eso sostuvimos que, sólo en parte, aceptábamos una eventual contraposición público/masa.

Más aun tendremos que hablar de la imbricación masa/público si nos referimos a la autocomunicación de masas; el propio Castells, quien acuñó la expresión, le atribuye esa misma propiedad de masas al referirla de esa modo. Suponemos que lo hace, primero, por extensión del concepto de medios de comunicación de masas a su objeto de estudio. También suponemos que lo hace a sabiendas de que, en la actualidad, ésta es la única forma en la que el público compuesto por personas privadas racionantes puede cumplir con los mismos requisitos que C.W. Mills enumera para esa categoría de público frente a la de masa; pero, finalmente, además también suponemos que lo hace en plena conciencia de que el fenómeno no se circunscribe sólo a un público o al público, sino que, efectivamente, su base sociológica es mucho más amplia y comprende también a las masas por la extensa y cada vez más heterogénea composición social de quienes acceden a las redes sociales y participan en ellas.

\subsection{Los sesgos ideológicos en la noción de masa}

En un intento por sintetizar cómo Habermas nos relata la historia de la opinión pública, si nuevamente nos retrotraemos al momento clave en el que, según él, surge el público como autopercepción de las personas privadas racionantes reunidas en sus roles de hombre y propietario, queda perfectamente claro el fundamento burgués de la institución en sus inicios. La institución de la publicidad burguesa fue masculina porque entonces la estructura familiar patriarcal estaba generalizada entre la población. Esta familia patriarcal era la que, en su calidad de esfera íntima, garantizaba la privacidad inserta en el público.

Así pues, la publicidad burguesa desde sus orígenes conllevó una fuerte restricción social en su composición que excluyó a las personas no propietarias, a las carentes de instrucción y a las mujeres. En el periodo en el que tuvo auténtica vigencia excluía, casi nada, a toda la población rural que en su práctica totalidad era analfabeta, al conjunto de la población femenina y amplias capas sociales urbanas que por lo general no disponían de otro medio de vida que ofrecer a la venta su fuerza de trabajo manual en el tráfico mercantil.

La institución de la publicidad burguesa nació con una indudable vocación elitista alimentada por un entonces incipiente capitalismo que veía crecer y expandirse el tráfico mercantil hasta al punto de forzar la recomposición del antiguo orden estamental para dar cabida en el juego del poder político a los intereses de los cada vez más ricos e influyentes burgueses. 
Hernández Rodríguez, C. E.

La imbricación y disolución de la masa en el público, sus consecuencias: la inestabilidad política de los sistemas liberales

La ideología detonadora de estos cambios fue la ideología liberal. Las ideas de la libertad e igualdad entre los hombres acabaron por prender en las cabezas de las personas en las nuevas capas sociales enriquecidas con el comercio e ilustradas gracias al extraordinario efecto en la producción literaria que trajo el invento de Gutenberg. Fue este conjunto de circunstancias el que provocó la autonomización de un público racionante y crítico del poder.

Ahora bien, la igualdad de oportunidades -como base formal de la igualdad-, que sólo en apariencia ponía al alcance de todas las personas la posibilidad de acceso a la propiedad, a la autonomía y al público como persona privada inserta en la publicidad burguesa, se empezó a revelar cada vez más limitada e imposible de lograr para el grueso de la población. Fue esa misma institución la que entonces se convirtió progresivamente en el ámbito preferente para dirimir todos los conflictos de intereses que concurrían en el tráfico mercantil precisamente por sus funciones de crítica y control del poder. La burguesía ilustrada, que hasta ese momento ejercía las funciones de control crítico del poder ya en el Estado liberal burgués de derecho, advierte que su esquema de dominación empieza a ser cuestionado desde la esfera pública por la irrupción de las masas en ella y por la progresiva ampliación de la base social de la publicidad burguesa. Es cuando la opinión pública, de instrumento de emancipación respecto de la dominación que había sido, empieza a ser considerada por la burguesía liberal como una nueva instancia de dominación, como una amenaza.

Visto de esta manera cabe entonces preguntarse ¿qué puede haber de negativo en que este proceso siga su curso natural hasta que el todo social integre esa esfera pública de control crítico del poder? ¿Acaso no supondría esto la democratización absoluta de la sociedad? ¿No será que, de manera tan lógica como predecible, eso es lo que ha estado sucediendo en la misma medida que el progreso y las garantías sociales ampliamente reclamadas por las sociedades contemporáneas se han ido extendiendo?

La que ocurrió entonces es que la reacción de los liberales fue radical. El liberalismo doctrinario elabora un discurso ad hoc con el que excluir a las proactivas masas de la esfera de la publicidad antes de que pudieran dar al traste con un orden social y económico para ellos tan adecuado a las funciones del control crítico del poder del Estado como instancia de dominación para que no pueda intervenir en el tráfico mercantil. En su consideración despreciativa hacia las capas sociales hasta ese momento excluidas de la esfera pública acuñan la categoría de masa para referirlas, categoría que pasará ser nuclear en su discurso.

Lo sorprendente es el éxito que tuvo, y que todavía mantiene en gran parte, esa categoría como paradigma sociológico sobre el que explicar el proceso de transformación económica, social y política del Estado burgués de derecho en el Estado social.

El término masa tiene un abstracto y oscuro origen a caballo entre la filosofía, la sociología y la psicología, pero en realidad no se definió por oposición al de público. El liberalismo doctrinario lo quiso definir por oposición a uno de sus preceptos

Vivat Academia. Revista de Comunicación. 15 junio 2020 /15 septiembre 2020, nº 151, 47-68 
Hernández Rodríguez, C. E.

La imbricación y disolución de la masa en el público, sus consecuencias: la inestabilidad

política de los sistemas liberales

ideológicos, el individualismo. Como es fácil comprobar que le ocurre a Le Bon y su cohorte de acólitos, la masa aparece desde sus primeras formulaciones como lo opuesto al individuo, y todavía en el curso de la discusión entre Canetti y Adorno éste último se muestra particularmente preocupado por:

[...]que la presión real de las categorías de masa y poder - cuya profunda interrelación usted bien ha advertido - ha ido aumentando hasta un grado tal que dificultan enormemente la resistencia del individuo contra ellas, así como su autoafirmación en tanto que individuo[...] (Canetti 2002, p. CXIX)

Además sabemos que el liberalismo pretendió excluir a una gran parte del pueblo de su participación política, y también Adorno insistirá todavía en esa idea radicalmente defendida desde Le Bon hasta Hanna Arendt: «[...] Me refiero a la presión ejercida por ese sinnúmero de personas[...], es decir, a la presión de las masas reales sobre la formación de la voluntad política. [...]» (op. cit. p. CXVIII).

Está claro que esto se debió al gran empeño que pusieron aquellos liberales decimonónicos y a los que habitaron el cambio de siglo en las primeras décadas del XX en preservar su orden elitista. Ese fue el resultado de un ingente legado teórico cuyo peso dejó una huella indeleble en el pensamiento humano que marcará a las sucesivas generaciones de estudiosos e investigadores. Nosotros creemos que la reacción más extrema en tal sentido fue la del universal filósofo hispano José Ortega y Gasset en su obra La rebelión de las masas. La virulencia con la que Ortega se despacha contra su «despreciado y despreciable» hombre-masa es patente a lo largo de esta.

Sin duda, a un lector de nuestro tiempo por fuerza le tiene producir un rechazo y una indignación más o menos intensos el progresar en la lectura de la obra de Ortega por lo que tiene de excluyente y exclusiva frente al público en general, justificadora de un orden social elitista. A modo de prueba, intentaremos en los siguientes párrafos desplegar una breve, aunque muy ilustrativa, crítica al pensamiento social de Ortega, no exenta de juicios morales, que resultará clave en la comprensión de la tendencia básica en la histórica hacia la imbricación de masa y público.

\subsection{La filosofía de Ortega y Gasset como ideología}

\subsubsection{Crítica al pensamiento social de Ortega}

La hipótesis básica de Ortega consiste en defender el orden social legado por el siglo XIX a toda costa, y lo hace pensando que todos sus logros se pudieron ver comprometidos por culpa de la relativa abundancia material y la promesa de mejoras en la calidad y en el nivel de la vida. Según él, desde los comienzos de la modernidad estos logros calaron en la conciencia media de las personas, proyectándolas hacia una vida cómoda, carente de metas y de los sacrificios que exige el lograrlas.

Para demostrarlo parte de la inconsistente convicción de que la mayoría de la sociedad no puede, ni debe, alcanzar la excelente condición de una minoría. Ella es la 
Hernández Rodríguez, C. E.

La imbricación y disolución de la masa en el público, sus consecuencias: la inestabilidad política de los sistemas liberales

que conlleva el exclusivo privilegio de la abundancia, y para ella él reserva un papel dirigente y protagonista frente a los demás. No hace el más mínimo esfuerzo para convertir en tesis tan desconcertante y descabellada 'hipótesis'; simplemente la sostiene, la reproduce y la desarrolla, repitiendo ad nausean sus prejuicios sobre una supuesta e ignota 'naturaleza' de orden universal.

\subsubsection{La educación como valor y derecho universal no discriminatorio}

El más elemental sentido común nos indica que la generalidad de las personas somos semejantes en cuanto a competencias y capacidades, a salvo de las naturales limitaciones físicas o mentales de unas pocas que tampoco son responsables de ellas y que por eso merecen una adecuación a sus involuntarias limitaciones. Sólo son muy pocos los que se desvían apreciablemente por encima o por debajo de la media. Esta realidad ha sido constatada en las sociedades contemporáneas precisamente con la extensión del derecho a la educación universal. Hoy en día, los gobiernos están más preocupados por lograr la eficacia de sus sistemas educativos y en evitar efectos indeseados como el fracaso escolar que en preparar a personas con distintas cualificaciones. La experiencia está demostrando que los países con los mejores sistemas educativos, los que logran extender y generalizar la formación de sus ciudadanos aumentando la calidad y cantidad de sus conocimientos, son también los que gozan de una mejor ventaja comparativa en la propia competencia económica del capitalismo global.

Con independencia de que esta formación contribuya más o menos a la estratificación en la sociedad, lo cierto es que una mayoría de población adulta preparada les ha reportado a esos países una incuestionable ventaja sobre otros, tal y como demuestran los ejemplos particulares de Japón, Alemania o Corea del Sur. También esto es lo que se puede inferir a partir del siguiente gráfico sobre la evolución de la ocupación en los países de la OCDE hace ya tres décadas:

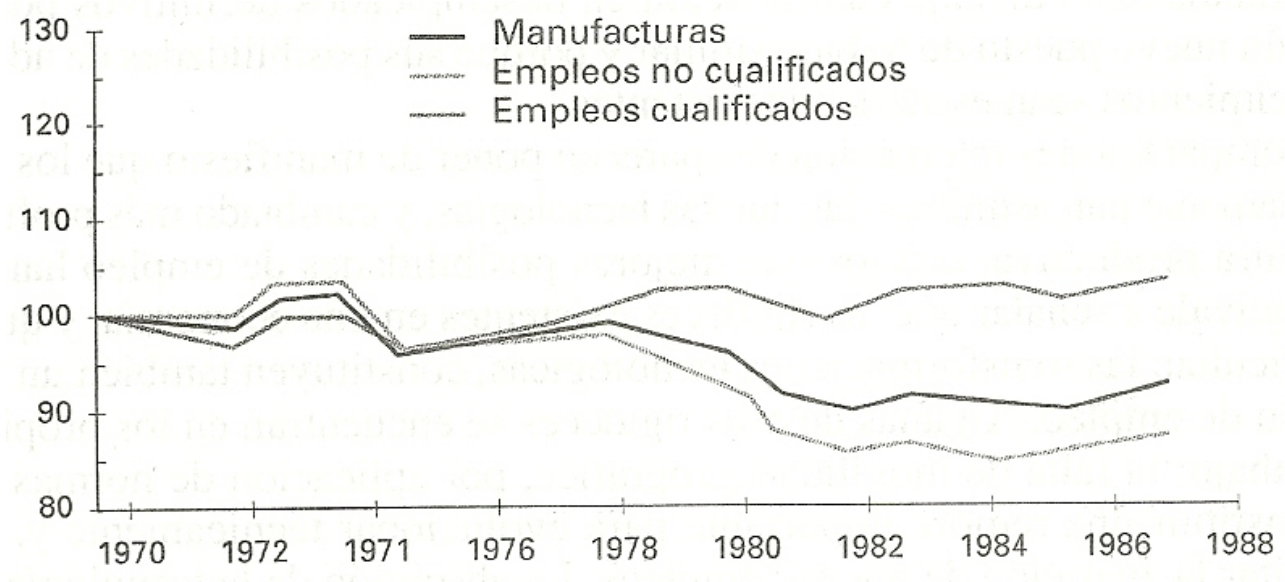

\section{Gráfico 1.}

Fuente: citado Requeijo: Cap. 4 de The OCDE Jobs Stud: Evidence and Explanations, OCDE 1994. (Requeijo 2002, p. 303). 
Hernández Rodríguez, C. E.

La imbricación y disolución de la masa en el público, sus consecuencias: la inestabilidad política de los sistemas liberales

Por otro lado, lo que también se ha hecho evidente es que la preocupación por la educación generalizada de la población también se ha trasformado en un clamor de generaciones enteras las cuales se han estado percibiendo como 'perdedoras' en los mismos términos que acuñará la ideología liberal clasista dentro de sociedades referentes de esta ideología, como la americana. Estas generaciones, a las que falsamente se las convenció de que su baja posición social relativa se debió a su falta de constancia en el esfuerzo por completar sus estudios y su preparación, ahora contemplan con inquietud que sus descendientes repitan sus mismos supuestos errores y se preocupan por estimularles para que logren una educación superior. Por lo general, los sistemas educativos pretenden ofrecer una aparente igualdad de oportunidades basada en la concesión de becas y ayudas para justificar el hecho de que las desigualdades terminen por prevalecer entre las personas, aunque ya vemos que su educación no es principalmente la causa de esa prevalencia. El colmo de los colmos es que hoy ni siquiera la educación superior es garantía de acceso a unas condiciones materiales de vida suficientes en muchos países desarrollados según los indicadores de la OCDE, particularmente en los términos de una media social muy devaluada por salarios bajos y trabajos precarios.

Pero además viene a resultar que este relativo engaño de la adscripción social según la formación ha sido revelado por la sociología. Distintitas investigaciones sobre la estructura social han demostrado que la igualdad de oportunidades no existe en ninguna sociedad desigual como la capitalista. (op. cit. pp. 174-182)

Salvo contadas excepciones, el potencial que la mayoría de las personas poseemos para nuestro desarrollo humano es muy similar según considera la UNESCO y, si se dieran las condiciones adecuadas, aproximadamente todos aportaríamos al esfuerzo común necesario para el desarrollo de la sociedad y la economía en igual medida. Lo haríamos con competencias asimilables sin excluir por ello a las personas discapacitadas.

\subsubsection{Los prejuicios elitistas de Ortega}

Qué contradictorio resulta Ortega cuando acusa a las masas de aspirar a la vida de las "minorías excelentes" y al mismo tiempo rebusca en la misma existencia de la distinción y la superioridad la explicación para la decadencia de Europa. Es la misma decadencia que él acaba por encontrar en la autocomplacencia de la época; como si desde su propia concepción de la superioridad no existiera otra motivación para esforzarse que no fuera precisamente la de obtener lo ya logrado por otros o, mejor aún para sus egoístas y miserables prejuicios, obtener aún más que ellos.

Sin pensar de otra manera que cómo lo hace él, la referencia para una mayoría de personas debería ser la ventaja en su envidiable prosperidad de las "minorías excelentes"; porque en realidad no hay ningún motivo para sospechar que el resto no se "mida" con ellas si, como él mismo afirma, aspiran a ocupar su posición social. Si tan evidente resulta que los placeres del arte y otros placeres de su privilegiada y abundante vida son la consecuencia de una meritoria existencia llena de renuncias,

Vivat Academia. Revista de Comunicación. 15 junio 2020 /15 septiembre 2020, nº 151, 47-68 
Hernández Rodríguez, C. E.

La imbricación y disolución de la masa en el público, sus consecuencias: la inestabilidad

política de los sistemas liberales

retos y desafíos ¿Por qué hemos de suponer que los demás estén llamados a llevar una penosa existencia de privaciones y necesidad sin llegar de ninguna manera a comprometerse en aceptar los retos que les plantee el mejorar sus vidas? ¿Cómo es que el resto no se da cuenta de los méritos que tienen que contraer para escapar a su pobre y triste destino de necesidad y servidumbre? ¿No será... porque el destino "marca" de una manera incondicional la posición social de cada uno en una estructura social determinada por su propia, atávica e ignota "naturaleza" ...?

Ortega no pretende así ni siquiera a la moderna ideología meritocrática que actualmente rige en las democracias liberales. Hoy, como expusimos en el subapartado anterior, la ideología liberal se obstina en explicar a las desigualdades sociales a partir de la responsabilidad de cada cual en saber adoptar las elecciones correctas dentro de un sistema que se supone lleno de verdaderas oportunidades. Con independencia de la relativa falsedad de este último postulado, lo cierto es que la teoría sociológica estructural-funcional (Parsons-Luhmann) considera a la movilidad dentro de la estructura social como un poderoso factor de estabilidad para el último capitalismo.

Ortega ni tan siquiera piensa así. Él reivindica una estructura social tradicional, rígida e inmutable, basada en un "ancestral orden natural del mundo" que selecciona y asigna desde su nacimiento a cada uno dentro de su posición social.

Está claro que lo que hay de más en todo el razonamiento orteguiano es el suponer que las minorías son "superiores" porque sí y el resto es "vago y ocioso" porque lo dice él. Esto no puede ser presentado ante la racionalidad científica más que como un mero prejuicio ideológico.

\subsubsection{Los orígenes y la evolución social de las democracias liberales}

Sin ninguna duda que lo anacrónico del pensamiento de Ortega hoy resulta evidente al comprobar que su visión elitista y excluyente de las mayorías en la organización y el gobierno de la sociedad ha quedado relegada a su venerado y vetusto siglo XIX.

En la actualidad nadie auténticamente competente se atreve a hablar de la sociedad democrática sin referirse a uno de sus ingredientes fundamentales, las "clases medias". Estas mayorías ciudadanas dentro de la estructura en las sociedades contemporáneas más democráticas serían el correlato del hombre-masa vulgar en el esquema orteguiano. Hoy por hoy, esas mayoritarias clases medias afortunadamente son las que deciden el rumbo de las democracias más avanzadas del planeta y son las que dan la necesaria legitimidad y estabilidad a los gobiernos constituidos por sufragio universal mediante su voto. Los procesos de toma de decisión política, el diseño e implementación de las políticas públicas, los cálculos electorales, las declaraciones públicas, los presupuestos de los Estados... todas las iniciativas de gobierno buscan la aquiescencia de las mayorías sociales representadas por las clases medias, aunque muchas veces lo hagan de forma más o menos engañosa. Todo esto 
Hernández Rodríguez, C. E.

La imbricación y disolución de la masa en el público, sus consecuencias: la inestabilidad

política de los sistemas liberales

incluso a salvo de las situaciones excepcionales que también son tratadas con la misma voluntad integradora en la opinión de esas mayorías.

Lo que se esconde detrás del pensamiento de Ortega no es otra cosa que el miedo a la realización de los mejores ideales democráticos: la emancipación social y política de las mayorías, de los pueblos sin escisiones internas de ningún tipo. Este proceso, el mismo que describe Habermas, puesto en marcha por los liberales hacia el final del siglo XVIII y durante la primera mitad del XIX con el establecimiento definitivo de la publicidad y de las revoluciones burguesas, lo ve él como una amenaza para los enormes logros que le suceden. No llega a comprender en ningún momento la lógica interna de la liberación de esas poderosas fuerzas sociales que son las propias masas, ni tampoco entiende sus consecuencias. Al revés, él las deforma grotescamente para lograr su finalidad de preservar su venerado orden social jerárquico y clasista.

Lo que ocurre con Ortega es que tiene una comprensión puramente instrumental del sistema democrático representativo. Para él éste no es más que un pretexto para la estabilidad política basado en la falsa apariencia del gobierno formal desde las mayorías. Por eso considera que es una fórmula ideal para «desactivar su innata propensión a la violencia como única razón de las masas» (Ortega y Gasset, 1979, 87). A esta estabilidad, y a la técnica, atribuye él el progreso logrado en el siglo anterior al suyo.

Basado en suposiciones y conjeturas, todas absurdamente avaladas por una experiencia histórica muy mal sistematizada por su peculiar «razón histórica», su argumentación pretende entonces ignorar el papel de las masas en el proceso de industrialización, en el logro de la suficiencia alimenticia y material de toda la sociedad, en la generación del excedente económico, en el inicio del camino hacia el crecimiento humano puesto en marcha por la alfabetización general de la sociedad, en el progreso de la libertad en todos los órdenes de la vida social: el cultural, el científico, el artístico...

Sucintamente, su visión es muy estrecha y timorata. Justamente se reduce a contemplar, asustado, los primeros y vacilantes pasos de ese nuevo destino común tan prometedor para la humanidad, tan pletórico de oportunidades. En tan colosal proceso sólo aprecia con alarma creciente una, para él, indeseable igualación social y económica de las personas que le aparta, junto a su venerada elite, del privilegio y la exclusividad, que le permite a cualquiera ser como son "ellos".

\subsection{Las transformaciones en el estado social}

La sociología se ha ocupado de estudiar y describir los cambios operados en el actual Estado social; precisamente lo ha hecho dando cuenta de todos estos aspectos positivos que Ortega no supo ver en los progresos de su tiempo. En línea con ese conjunto de avances es fácil constatar que la misma masa ha experimentado una absoluta transformación desde su composición social originaria. Ahora aparece integrada por los coetáneos trabajadores de alta cualificación desplazados desde los 
Hernández Rodríguez, C. E.

La imbricación y disolución de la masa en el público, sus consecuencias: la inestabilidad política de los sistemas liberales

sectores primario y secundario de la economía por efecto de la terciarización en una sociedad y una economía que apenas sí puede ya dar más ocupación en el sector servicios. Aparece también integrada por las mujeres insertas en el tráfico mercantil a través de su incorporación masiva al mercado laboral por el cuestionamiento racional de la familia patriarcal tradicional como instancia de dominación de género. $Y$, finalmente, la masa aparece integrada por la totalidad de las personas del mundo rural y urbano que se han beneficiado de la generalización de una instrucción cada vez más exigente, preñada de mayores y mejores contenidos, que cuenta con el auxilio de novedosos y más eficaces métodos pedagógicos y de nuevos soportes para su difusión instantánea en la sociedad del conocimiento a través de las TIC (nuevas tecnologías de la información) y las redes digitales.

También Daniel Bell se orienta en esta misma dirección al realizar su exhaustivo análisis de los cambios operados en la estructura social de las sociedades postindustriales. Aunque se trate de una conclusión obtenida del modo mucho más detenido y detallado en él que realiza dicho análisis, avalado por un sinfín de datos, a lo a largo de su obra El advenimiento de la sociedad post-industrial, la siguiente cita es muy ilustrativa:

La cuestión de qué constituye la revolución de nuestra época es demasiado amplia y vaga. Evidentemente, es una parte tecnológica. Pero también es política en cuanto que, por vez primera, estamos observando la inclusión en la sociedad de vastas masas de gente, un proceso que implica la redefinición de los derechos sociales, civiles y políticos. (Bell 2006, pp. 225-226)

Aun así, consideramos pertinente ofrecer, a modo de prueba de la realidad y de sus consecuencias del proceso, la previsible evolución de la alfabetización de la mujer por regiones mundiales, en cuanto que genuino representante del pueblo originariamente excluido del público. Será la siguiente para el primer decenio del siglo XXI según la UNESCO:

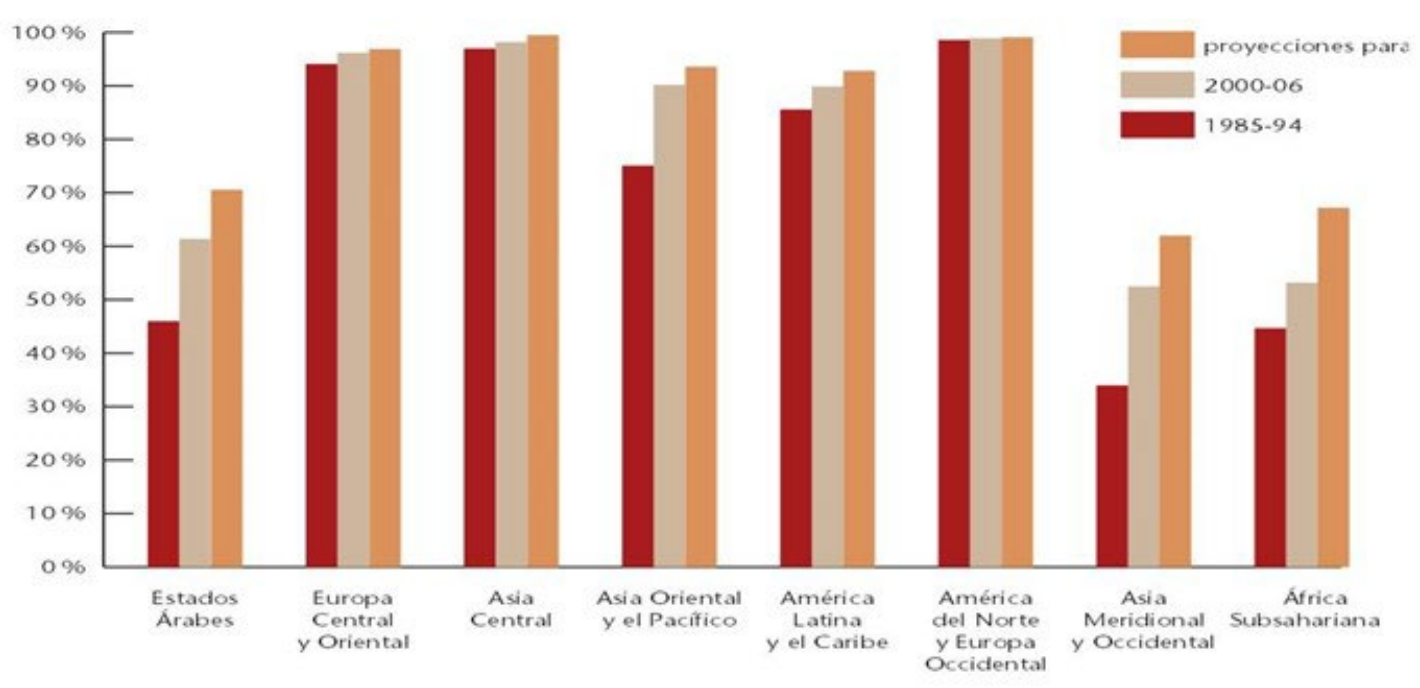

Gráfico 2: tendencias de las tasas de alfabetización de la mujer, por región (\%). Fuente secundaria: El desafío mundial de la alfabetización. 
Hernández Rodríguez, C. E.

La imbricación y disolución de la masa en el público, sus consecuencias: la inestabilidad política de los sistemas liberales

Entonces, la oportuna y procedente explicación ofrecida por la Escuela de Frankfurt sobre los efectos alienadores que la industria cultural produce en las masas, y la más específica y acertada observación de Habermas sobre la pérdida de sus funciones críticas del poder en la publicidad burguesa originaria con las transformaciones que trajeron la sociedad de masas y el Estado social, podrían muy bien no ser más que un precio a pagar y una mera etapa de transición hacia a la mayoría de edad de un público racionante integrado por una mayoría social, ahora sí, de citoyens, no de bourgeois. Un público en el que definitivamente se acabarían por disolver las masas mediante el ejercicio de la función del control crítico del poder político.

En este punto, tal y como nos habíamos comprometido, aprovechamos para ofrecer una explicación contrastada con la habermasiana preocupación por la pérdida de notoriedad pública crítica y por los efectos de la publicidad manipuladora en las masas, dada su aparente aquiescencia y su actitud aclamativa y plebiscitaria hacia al poder del Estado. En línea con lo que ya argumentábamos, señalamos como un relevante motivo para ese aprecio de lo público a la percepción que tienen las propias masas por la existencia de una instancia de dominación dentro del tráfico mercantil a la que experimentan como a una verdadera amenaza, mayor que la del Estado, sobre sus derechos sociales y sobre sus aspiraciones a una vida mejor. Nos referimos a la permanente presión de los mercados, del capital, para mermar sus condiciones y derechos sociales.

Así pues, las nuevas masas, transformadas desde sus limitaciones sociales originarias durante el Estado liberal burgués de derecho por el constante progreso social hacía el mismo Estado social de masas, proceden a constituirse en público con el verdadero atributo que poseía la persona privada durante la vigencia de la publicidad burguesa para legitimarse ante esa instancia, el de la instrucción. Resulta evidente que los atributos de la masculinidad y la propiedad tan sólo eran limitaciones impuestas por la tradición y por las características del orden social y económico propios del Estado liberal burgués de derecho, y también es evidente que la generalización de la educación ha situado a los antaño excluidos en posesión del preciado atributo de la instrucción, imprescindible para el ejercicio de la función crítica del poder como personas privadas que integran el público racionante. A esto mismo es a lo que se refiere Michel Foucault cuando, en Diálogo sobre el poder y otras conversaciones, afirma:

[...] Ahora bien, los intelectuales han descubierto, después de las recientes luchas, que las masas no los necesitan para saber; ellas saben perfectamente, claramente, mucho mejor que ellos; y además lo dicen muy bien. Sin embargo existe un sistema de poder que interpreta, prohíbe, invalida ese discurso y ese saber[...] Lucha contra el poder, lucha para hacerlo desaparecer y herirlo allí donde es invisible y más insidioso, o lucha por una «toma de conciencia» (hace tiempo que la conciencia como saber fue adquirida por las masas y que la conciencia como sujeto fue tomada, ocupada, por la burguesía) [...] (Foucault 2012, p. 32). 
Hernández Rodríguez, C. E.

La imbricación y disolución de la masa en el público, sus consecuencias: la inestabilidad política de los sistemas liberales

Es bien conocida la importante contribución que hicieron las ideas de Foucault a la revolución parisina de mayo de 1968. Aquella fue una auténtica demostración de movilización de las masas en la que dieron una importante lección de civilidad con la renuncia expresa a cualquier intento de derrocar al poder político por una acción revolucionaria violenta. El movimiento social se conformó con forzar la convocatoria de elecciones anticipadas por De Gaulle, presiente entonces de la República Francesa. Así quedo perfectamente demostrado el cambio cualitativo de las masas ya en esas históricas fechas, por lo que Foucault no tuvo ningún problema a la hora de proclamar su autosuficiencia, liberándolas así de su negativa condición de monstruoso mito destructor de civilizaciones.

Ya para terminar no queremos dejar de reseñar los hechos protagonizados por amplios sectores sociales para encarar las duras condiciones creadas por la referida crisis estructural y sistémica del capitalismo en el año 2008. La experiencia en las movilizaciones masivas, de masas, ha revelado bajo la luz de tales acontecimientos la actitud madura y responsable de un auténtico público que ya cuenta, a través de la autocomunicación de masas, mediante el encuentro y el debate en las redes sociales en la web, con un ámbito ideal para la realización de sus funciones de control crítico del poder en las taxativas condiciones que exigía C.W. Mills para su consideración como público de esas amplias y heterogéneas mayorías sociales.

La estrecha limitación que Habermas proponía para la constitución de un público que cumpliera con esas mismas exigencias en las condiciones del Estado social mediante la recomposición de la notoriedad pública crítica dentro de unas organizaciones de masas más transparentes y democráticas, no parece ya ser la única vía. Las movilizaciones espontáneas y asamblearias facilitadas por las redes sociales al margen de los partidos y sindicatos tradicionales así lo demostraron y todavía se han seguido demostrando con la movilización de los chalecos amarillos en Francia. Pruebas todas ellas también incuestionables de que la imbricación de masa y público resulta cada vez más una clara evidencia que se afianza como tendencia histórica positiva.

Tampoco nuestra explicación puede adolecer de la siguiente consideración sin quedar claramente sesgada e incompleta. A la hora de referirnos a ese fenómeno de la expansión y la extensión del conocimiento a partir de la alfabetización como la calve para alcanzar su condición de público por las masas, es necesario referirse a la brecha que se produce entre los países más desarrollados y la inmensa mayoría de la humanidad que reside en los hoy todavía mal llamados países en vías de desarrollo. Entre los primeros se encuentran esencialmente aquellos países pertenecientes a la órbita de los países occidentales en los que se ha venido centrando por sus múltiples autores nuestra historia de la emancipación de la opinión pública.

Un problema nada desdeñable para el resto de la humanidad es el de la distancia cada vez mayor de conocimiento que se interpone entre ellos y los países occidentales precisamente por ese factor liberador de las masas que se hace posible gracias al empleo generalizado de las nuevas tecnologías de la información. Pero si

Vivat Academia. Revista de Comunicación. 15 junio 2020 /15 septiembre 2020, nº 151, 47-68 
Hernández Rodríguez, C. E.

La imbricación y disolución de la masa en el público, sus consecuencias: la inestabilidad política de los sistemas liberales

bien es verdad que el retraso es considerable para una mayoría de ellos, no es menos cierto que la velocidad de difusión de las TIC (Tecnologías de la información) es superior al de la extensión desde su nacimiento en los países pertenecientes a la OCDE para el caso del grupo de los llamados BRIC.

El brusco reequilibrio de la economía mundial a favor de la potencia económica de esos países así lo sugiere. Cabe albergar la esperanza de que en un futuro próximo el resto de los países también se beneficiará de estos importantes avances favorecedores del desarrollo y la extensión del conocimiento, situando a sus actuales masas sociales en condiciones de forzar los cambios institucionales que las liberen de su condición de excluidas para su participación crítica en el poder político de sus sociedades.

\section{CONCLUSIONES}

Al comienzo de nuestro análisis nos proponíamos explicar una de las claves de la actual crisis de legitimación política de los sistemas liberales a partir las transformaciones experimentadas por la institución de la Opinión Pública, concretamente por la imbricación de masa y público.

Recordemos que, tras citar a Habermas, determinamos la relevancia de sus hallazgos para hacer una reinterpretación que nos permitiera comprender una clave de la crisis de legitimidad institucional a la que asistimos. Concretamente nos referíamos a la ampliación de la base social que constituye a la opinión pública como resultado de las transformaciones del Estado liberal burgués de derecho camino hacia al Estado social de derecho.

En tal sentido, lo que nosotros consideramos relevante es la socialización del Estado a la que se refiere Habermas como una consecuencia complementaria de la estatalización de la sociedad. Esta fusión de sociedad y Estado es precisamente la que exige que el ámbito de la opinión se amplíe a la sociedad en su conjunto para prevenir que, en esa pugna entre el poder político y el social, quiera prevalecer el poder político como instancia ilegítima de dominación frente al poder social.

Efectivamente, esto pudo resultar así en el pasado porque la función deslegitimadora de las mayorías en la formación de la voluntad política con la que se ha venido empleando la categoría de masa frente a la de público como base social de la opinión, ha servido a su objetivo de ocultar la naturaleza desigualitaria del orden político y social liberal.

Hoy, la inevitable e imparable imbricación de estas categorías, masa y público, una tendencia histórica positiva en el progresivo afianzamiento de la opinión pública como instancia de control crítico del poder político, es justamente lo que se ha convertido en la causa de la deslegitimación de ese mismo orden político y social, estructuralmente necesitado del aval público debido al sufragio universal. Con la extensión social de la racionalidad, ahora ese mismo orden es percibido por las 
Hernández Rodríguez, C. E.

La imbricación y disolución de la masa en el público, sus consecuencias: la inestabilidad

politica de los sistemas liberales

transformadas masas en público racionante como una instancia de dominación al servicio de intereses sociales y económicos que no son los suyos.

La crisis económica y social puso en entredicho todo el entramado institucional al que hoy se percibe como nunca antes responsable de la situación del progresivo empobrecimiento y proletarización de las clases medias. Esto las está llevando a dispersarse críticamente entre aquellas opciones políticas que no sean las que en el pasado reprodujeron el orden social desigual, o bien a inhibirse ante ellas. Después de todo, estas últimas lo hicieron bajo la promesa falaz de una prosperidad igual para todos apoyada en un crecimiento económico sostenido. El resultado es que muchas de las opciones alternativas que hoy irrumpen en el escenario político son abiertamente contrarias al orden político institucional liberal por haber ocultado y justificado su naturaleza desigualitaria.

\section{REFERENCIAS}

Bell, D. (2006). El advenimiento de la sociedad post-industrial. Madrid: Alianza Editorial.

Canetti, E. (2002). Obras Completas I, Masa y Poder. Madrid: Galaxia Gutemberg /Círculo de Lectores.

Castells, M. (2009). Comunicación y Poder. Madrid: Alianza Editorial S.A.

Dewey, J. (2004). La opinión pública y sus problemas. Madrid: Ediciones Morata S. L.

Foucault, M. (2012). Diálogo sobre el poder y otras conversaciones. Madrid: Alianza Editorial.

Habermas, J. (2011). Historia y crítica de la opinión pública. La transformación estructural de la vida pública. Barcelona: Ediciones G. Gili, S.A. de CV.

Horkheimer, M. (2002). Crítica de la razón instrumental. Madrid: Editorial Trotta.

Grunig J. E. y Hunt T. (2003). Dirección de relaciones públicas. Barcelona: Ediciones S.A.

Ortega y Gasset, J. (1979). La rebelión de las masas. Madrid: Alianza Editorial.

Requeijo, J. (2002). Economía Mundial. Madrid: McGraw-Hill Interaemericana de Esapaña, S.A.U.

\section{AUTOR:}

\section{Ciro Enrique Hernández Rodríguez}

Profesor en la Facultad de Ciencias Sociales y de la Comunicación en la Universidad de La Laguna adscrito al Departamento de Ciencias de la Comunicación y Trabajo 
Hernández Rodríguez, C. E.

La imbricación y disolución de la masa en el público, sus consecuencias: la inestabilidad

política de los sistemas liberales

Social en el Área de conocimiento Comunicación Audiovisual y Publicidad. Diplomado en Ciencias Políticas (UNED), Licenciado en Ciencias de la Información especialidad Periodismo (ULL), Máster Universitario Filosofía, Cultura y Sociedad (ULL), Doctorado en Nuevos Modelos Periodísticos (UMH). Además de ser miembro del Comité de Dirección de la Sociedad Latina de Comunicación Social, no solo ha participado en las sucesivos Comités Organizadores de sus Congresos y ha ejercido como moderador en sus mesas temáticas, también ha publicado comunicaciones y ponencias. Ha participado en otros Congresos académicos aportando sus colaboraciones. Ha sido Coeditor de la revista de Comunicación Pangea por un periodo de dos años, ha publicado artículos de investigación en Vivat Academia, Miguel Hernández Comunication Journal, Revista Mediterránea de Comunicación. Además, tiene dos publicaciones en la serie Cuadernos Artesanos de Comunicación Social: Los barrios chinos de la prensa tinerfeña de 2007 y El papel de la prensa tinerfeña en 'crisis de las pateras' de 2006, y capítulos en otras publicaciones de esta misma serie. En la actualidad imparte las asignaturas de Tecnología en Periodismo, Opinión Pública y Comunicación Audiovisual: Televisión y Radio Informativas.

chernanr@ull.es 